\title{
Potential Implications of Mail Delivery Conversion on Older Adults' Risk of Falls in the Winter
}

Jovana Sibalija ${ }^{1}$, Mallory L. Ciminsky', Katharine Fuchigami', Marie-Helene L.S He', John Trevithick', Geoff Bickerton ${ }^{3}$, Aleksandra Zecevic ${ }^{2}$

${ }^{1}$ Department of Health Sciences, Western University

${ }^{2}$ University of Western Ontario

${ }^{3}$ Canadian Union of Postal Workers

No conflicts of interest declared.

\section{Abstract}

In December 2013, Canada Post announced they would be converting approximately five million households from door-to-door mail delivery to community mailboxes (CMB). The decision was made to address decreasing letter mail volume and operating losses experienced by the crown corporation. The CMBs will be phased in over the five years mainly in urban areas across the country. The decision to convert to CMBs makes Canada the only among the G8 countries to end home delivery of mail. As a result, no research exists on the implications of the change. Particular concern has been raised over how the conversion will affect older adults. One area that needs examination is the consequences of the CMBs delivery model on fall rates among older adults in the winter. Falls are common among seniors, with 20-30\% community dwelling older adults falling each year. The risk of falling is increased in the winter when there is snow and ice on the ground. Injuries dues to falls consume a great deal of healthcare resources. The purpose of this scoping literature review was to determine: What are the implications for the elderly population of Canada Post's decision to convert home delivery of mail to community mailbox delivery? Specifically, the review focused on how the conversion may impact fall rates among older adults in the winter.

\section{Introduction}

On December 11, 2013 Canada Post Corporation (CPC) announced that it would be converting over 5 million residences from home delivery to community mailbox (CMB) delivery. The conversion to CMBs is part of Canada Post's 5 Point Action Plan aimed at ensuring the long-term financial sustainability of the crown corporation and addressing shifting consumer needs (1). Canada Post also states the decision to convert was only taken after extensive consultation with the public. From May to September
2013, Canada Post representatives held public consultations about postal services in 46 communities across Canada. Public feedback was also obtained via letters and on-line written submissions (2). The conversion targets the one-third of Canadians that currently receive door-to-door mail delivery, the majority of whom reside in urban areas (3), and will be phased in over five (2014-2019) years across the country (1). 
The conversion makes Canada the first among the G8 leading industrial countries to eliminate home delivery of mail (2). As a result, no published research exists on the implications of such a change. In particular, it is not known how the conversion will impact the lives and well-being of older adults in Canada. Older adults represent the fastest growing segment of the Canadian population (4). Increasing age is associated with an increased risk of morbidity and mortality. Falls are a particularly important health concern for this population. Older adults are at an increased risk of falling due to factors such as, muscle weakness, gait and balance issues, vision problems, and living with a chronic disease or disability (5). Falls can have serious implications on health and well-being of older adults. Falling can lead to injuries, such as fractures and concussions (5). Falling can also impact mental health, resulting in a fear of falling, confusion, isolation, and depression (5). The purpose of this paper was to conduct a scoping literature review to gain an understanding of the potential implications for the older adult population of Canada Post's decision to convert home delivery of mail to community mailbox delivery. Specifically, the review focused on how the conversion may impact fall rates among older adults in the winter, a time of year when the risk of falling is increased.

\section{Methods}

The databases CINAHL, Academic Search Complete, and PubMed were assessed to search for information regarding older adults, falls and any academic literature on mail delivery. The key words used in the searches were: "seniors" OR "older adults", "mail delivery", "falls”, "injuries", "winter", and "health care costs". A total of 534 articles were identified and 8 were included in this scoping review. Articles were excluded (526) because they were irrelevant (i.e., did not focus on falls in older adults or were not related to mail delivery) were duplicates, or were not written in English. Although a date limit was not imposed, the included articles were written between 1988 and 2015 .
In addition to peer-reviewed literature, we also examined federal government reports, and reports by Canada Post, Statistics Canada, the Public Health Agency of Canada, Federation of Canadian Municipalities, United Way, and the Ontario Coalition of Senior Citizen's Organization. Newspaper articles and TV media sources were also examined to gain an understanding of public opinion on the issue and the status of the conversion in communities across Canada. One of the co-authors (GB), also an employee of the Canadian Union of Postal Workers at the time of the study, identified additional sources of information about postal worker injuries and the views and concerns of older adults about the conversion. A total of 21 relevant sources of gray literature, published from 2007 to 2015, were included in this review. The information collected from all sources was charted, analyzed and prominent themes were identified.

\section{Results}

\section{Canada Post's Reasoning for the Conversion}

One of the main reasons for the conversion is the decrease in letter mail volume that Canada Post has been experiencing since 2006 (1). This decrease is due to the increase in the number of $\mathrm{Ca}$ nadians using electronic communication. Bills and other documents traditionally delivered by mail are now delivered electronically. By 2020, letter mail is projected to decrease by $26 \%$ while parcel delivery is projected to increase by $26 \%$ (6). According to Canada Post, the CMBs are a more secure, convenient and cost-effective method for delivering mail. The CMBs will be located close to residential homes and Canadians will be able to access the boxes by a key, 24 hours a day seven days a week, which will only open their designated compartment, ensuring that their mail is stored safely until retrieved (1). The use of CMBs also brings financial benefits to Canada Post as door-to-door mail delivery is twice as expensive as using the CMBs. The Conference Board of Canada reports that by 
2020,Canada Post will experience a projected annual operating loss of approximately $\$ 1$ billion (6). The conversion to CMBs is expected to cut the projected $\$ 1$ billion deficit by $\$ 576$ million (3).

The use of the CMBs enables Canada Post to reduce labour costs, as thousands of employees are expected to retire between 2015-2019 alleviating the need to hire more postal workers (1). The CMBs are perceived by Canada Post as an opportunity to bring health and social benefits to Canadians. According to Deepak Chopra, CEO of Canada Post, CMBs will encourage and increase physical activity, especially for older adults, as individuals will have to walk more to retrieve their mail (7).

\section{Public Opinion and Controversy Surrounding the Conversion}

While Canada Post states the conversion is beneficial to both Canadians and the company itself, an analysis of media and community reports demonstrates that the decision has elicited opposition from various groups in society. Particular concern exists around how the change will affect older adults, as they are a vulnerable population. The Ontario Society (Coalition) for Senior Citizens' Organizations (OCSCO) expressed concern that ending door-to-door mail delivery can increase the cost of living for older adults with mobility or cognitive issues as these individuals may have to now pay someone to retrieve their mail (8). The organization also states that $30 \%$ of the older adult population is not computer literate or does not have access to technology, which limits their ability to access mail nline. Older adults who do not use the computer and also choose to not walk to their CMB, or do so infrequently, would have limited access to communication and important information such as bills and pension cheques (8).

Municipalities have also expressed their opposition to the change in mail delivery. The Federation of Canadian Municipalities reported that Canada Post did not properly consult with municipalities or considered issues of land use planning, service delivery, and the responsibilities of local governments when the decision to convert to CMBs was made (9). The planning department in the city of Burnaby, British Columbia reports that the city is concerned over the security of residents' private information and property as Canada Post has not provided any evidence to demonstrate that CMBs are secure and cannot be broken into (10). The city is also concerned over the impact of CMBs arbitrarily located on city property. CMBs run the risk of costing the municipalities more, as local governments would have to be responsible for snow and ice removal around the boxes in the winter. In addition, local governments could be potentially liable for injuries and accidents that occur around CMBs on city-owned property (10). Safety is another concern. The city of Burnaby was apprehensive over the safety of older adults and those with mobility issues when using CMBs. For example, the boxes might be placed in high traffic areas or may block traffic sight lines and sidewalk space. This may prevent individuals in wheelchairs from accessing the CMB or put them at a higher risk of encountering environmental hazards (10).

Other interest groups opposed to the conversion include the Canadian Union of Postal Workers (CUPW), the New Democratic Party of Canada (NDP) and the Liberal Party of Canada. These groups believe the conversion is a step towards privatizing Canada Post and are also concerned with the way the CMBs could negatively affect older adults and those with mobility issues (3). In fact, in October 2014, CUPW announced they would be taking Canada Post to federal court over this issue to try to stop the conversion to CMBs. The union argues the change violates the rights of older adults and those with disabilities under the Canadian Charter of Rights and Freedoms (11). The mayor of Montreal, Denis Coderre, announced in February 2015 that he would be looking into joining CUPW's legal challenge to try to maintain home delivery of mail in his city (12). Other municipal leaders and politicians, such as Toronto major John Tory and Halifax MP Geoff Regan, are also opposed to the mail conversion and both have expressed 


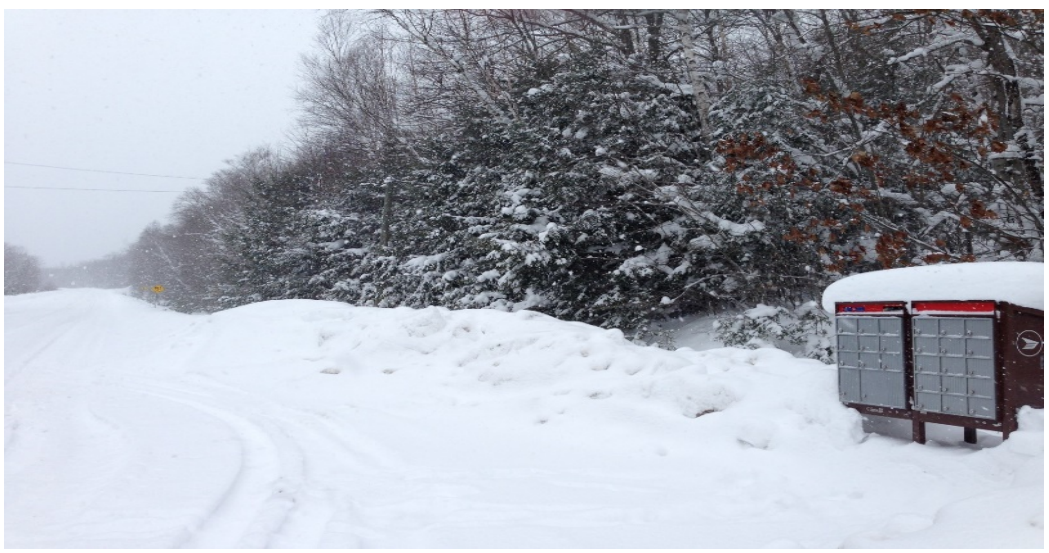

Figure 1. An example of a community mail box covered in snow and ice in the winter time.

concern for the safety of older adults while using the boxes $(13 ; 14)$.

\section{Falls among Older Adults}

Given the concerns over the safety of older adults, one potential implication of this conversion that needs to be examined is determining how the use of CMBs will influence older adults fall rates in the winter. This issue needs to be addressed as approximately $30 \%$ of community dwelling older adults fall each year in Canada. Falls are the leading cause of injury-related hospitalizations among older adults, accounting for $85 \%$ of all injuries (5). The majority of fall-related injuries are broken or fractured bones (35\%) and over 1/3 of fall-related hospitalizations among older adults are due to a hip fracture (5). Falls are the direct cause of $95 \%$ of all hip fractures, and a hip fracture due to a fall results in death in $20 \%$ of cases (5). Therefore, falls can have serious and at times, fatal consequences for older adults. The Public Health Agency of Canada (2014) reports that over one third of older adults who are hospitalized for falls are discharged to long-term care homes, meaning that these individuals are no longer able to function and live independently after suffering a fall (5). Furthermore, the number of deaths due to falls increased by $65 \%$ in just 5 years from 2003 to 2008 (5).

Falls among older adults are exacerbated in the wintertime when there is snow and ice on the ground (Figure 1). Although falls can happen on any ground and surface, $16 \%$ of falls are due to walking on snow or ice (5). In fact, in 2010-2011, 7,138 Canadians were hospitalized for injuries sustained from falling on ice, and more than half of those hospitalized were aged 60 and older (15). This is similar to findings related to injuries caused by slipping on snow and ice in a study conducted in northern Sweden. Bjornstig, Bjornstig, \& Dahlgren (16) concluded that slipping on ice/snow during winter caused 3.5 injuries per 1000 habitants/year in Umea health district. It was shown that fracture rates in this region were 1.7 per 1,000 inhabitants per year. Findings from England and Denmark also showed similar trends. A report from England stated that when $70 \%$ of walking surfaces were covered by ice and snow there were 9-16 injuries per 100,000 people per day (17). A report from Odense in Denmark showed that the risk of falling was 14 times higher during snowfall than during normal winter weather. Another Danish study found that the injury and fractures rates are 6-9 times higher on icy than on snowy surfaces (18).

\section{Postal Worker Falls and Injuries}

Due to the fact that falls are common occurrences among older adults and that the risk of falling is increased during icy conditions, it is hypothesized that older adults may experience falls while retrieving mail from their CMBs in the winter. This hypothesis stems from a study conducted by Bentley \& Haslam (2001) that identified risk factors for 
slip, trip and fall accidents (STFA) of postal workers during the delivery of mail in the United Kingdom (19). Key factors in STFA accidents included slippery underfoot conditions, non-weather related environmental hazards, poor slip resistance from footwear, unsafe working practices, management safety practices, and underlying organizational influences. Slipping accidents occurred on ice (46\%), wet grass (24\%) and snow (17\%). These findings demonstrate that the risk of falling is increased in the winter as the majority of accidents occurred on snow and ice. STFA represented the largest category of accidents and lost time within the delivery function of the Royal Mail, with STFA comprising one third of all reported accidents (19). Canadian postal workers also experienced incidents similar to the ones described by Bentley \& Haslam. According to a CUPW report for 2011, 155 letter carriers experienced a fall, 520 slipped and 245 tripped while working (20).

The Canadian data and the Bentley \& Haslam study demonstrate that falls do occur amongst postal workers during the delivery of mail. This has the potential to translate to older adults falling while retrieving their mail from the community mailbox. Older adults will be exposed to similar weather conditions and environmental hazards faced by postal workers, such as slipping on icy sidewalks, wearing improper footwear and facing obstructed pathways (19). The hypothesis is also supported by research from the Public Health Agency of Canada (5), which found that ice and precipitation can create barriers to safe access to roadways, sidewalks and buildings. Winter conditions can prevent proper use of assistive devices, as canes and walkers are more likely to slip, and tires on wheelchairs and scooters can lose traction or become obstructed. These risks are worsened when pedestrians increase their walking speed because of the cold.

In the first year of the implementation of the CMB conversion, reports of falls and injuries among older adults around the CMBs have emerged. In February 2015, an 81-year-old man from Windsor fell while retrieving mail from his
CMBin (21). A similar incident occurred in the winter of 2014, when a 77-year old woman fell while walking to her CMB (22). Both falls were due to a build-up of snow and ice around the mailboxes and the area surrounding them. Both falls also resulted in injuries. The Windsor man fell and hit his head, requiring eight stiches, around his eye (21). The woman from Kingston reported injuring her knee, making it difficult to sit (22). These two cases highlight the risks and consequences that the environment surrounding the CMBs pose in the winter for older adults. Both of the accidents occurred in areas where CMBs existed before the conversion. The conversion has the potential to increase falls and fall-related injuries among older adults, as the CMBs will be implemented in neighborhoods that were not originally planned to have the communal mailboxes (3). The built environment, in the soon to be converted areas might not be designed to accommodate the CMBs. As a result, factors such as the best location to place the boxes, snow removal policies and lighting around the CMBs might not be considered during neighborhood planning. This lack of consideration of the factors described earlier has the potential to create hazardous conditions around the CMBs, increasing the risk of falling.

\section{Implications for Healthcare Costs}

Falls on snow and ice have important implications for healthcare system resources. Injuries due to falls can result in increased healthcare costs. Beynon et al. (23) identified the cost of emergency hospital admissions for falls on snow and ice in England during winter 2009/10 which was characterized by low temperatures, depleted grit stocks and untreated surfaces. It was found that in the first two weeks of January 2010, admissions to emergency ward (due to falls on snow and ice) and the number of performed trauma operations doubled at one hospital in the South-West of England, which resulted in an additional cost of $\$ 367,172$. The study found that the number of emergency admissions for falls on snow and ice was 18 times 
greater in 2009/10 $(\mathrm{n}=16,064)$ than $2007 / 08(\mathrm{n}=$ 890), and the admissions rate was highest among men aged 80 and over (23). The study concluded that in England, the cost of emergency admission for falls on snow and ice between December 1, 2009 and February 28, 2010 was 42 million GBP (23). This study demonstrated that the risk of falling is increased in the wintertime, leading to increases in hospital admissions and healthcare costs (23). Given the fact that older adults are already prone to falling in normal conditions, walking to the community mailbox in winter conditions has the potential to increase fall rates among older adults, resulting in injuries and increased healthcare costs.

Falls cost the Canadian healthcare system large amounts of money and resources. According to the Public Health Agency of Canada (2014) individuals hospitalized due to falls remain in the hospital for 9 days longer than those hospitalized for any other cause (5). In 2008-2009, the average acute length of stay for a fall-related injury in Canada was $70 \%$ longer (15.1 days) compared to the average length of stay for all other causes of hospitalization excluding falls (8.9 days) (24). This translates to a need for the equivalent of 13 additional 200-bed hospitals, where all of the beds would be filled with older adults with fall-related injuries every day of the year (24). When examining age and healthcare costs, falls of older adults across Canada cost the healthcare system $\$ 2$ billion annually, which is 3.7 times greater than the costs for adults aged 25-64 (5). The hospital costs for in-patients seriously injured from falls in an acute care hospital were $\$ 30,696$ greater than the costs for patients who did not fall during their hospital stay (25).

As falls are expensive and prevalent among seniors, it is important to note that the number of older adults in Canada is increasing. In 2011, an estimated 5 million Canadians, or $15 \%$ of the population were 65 years or older (26). This number is expected to double and reach 10.47 million older adults by 2036 (26). This means that the estimated number of older persons who will fall at least once in 2036 will increase to 3.3 million (26), potentially creating substantial burden on the healthcare system's resources.

\section{Discussion}

Based on the scoping review of the literature, we found that little information exists on the implications of the conversion from home delivery of mail to CMBs, as Canada is the first developed country to implement such a change. However, inferences on the potential implications of the change can be made from the published literature, especially from research studies on falls among older adults and injuries of postal workers during mail delivery. This review revealed concerns over older adults' ability to physically access CMBs and the hazards they may encounter. In the first year of implementation, news outlets reported stories of some older adults slipping and injuring themselves on the ice and snow around CMBs. Therefore, it can be recommended that research is urgently needed to determine how the mail delivery conversion will influence fall rates among older adults in the winter. Studies are needed to investigate if and why older adults might be falling during retrieval of mail from the CMBs. Studies should also examine the environments surrounding the CMBs in the winter, such as the location of the $\mathrm{CMB}$ in a neighborhood, the frequency of snow removal, and the presence of adequate lighting, to gain an understanding of how environmental factors impact safety and fall risk when retrieving mail. More research is also needed to further investigate the potential implications of this change on healthcare costs related to injury due to falls. Potential savings for a corporation on a federal level might result in increased government healthcare spending on a provincial level in Canada.

Another recommendation would be to further explore the relationship between CMBs use and the potential benefits of increased activity levels of older adults. Canada Post has reported that CMBs would bring indirect benefits such as increased activity levels for people walking to retrieve their 
mail from CMBs (2). Moreover, environmental impacts are an important area of potential research. For example, Canadians driving to their CMBs may contribute to an increase in carbon dioxide levels, raising concern for global warming. Calculating the amount of carbon dioxide generated from drives to and from CMBs can provide some insight into the environmental impact of the conversion.

Older adults living alone may be negatively affected by this conversion. Currently, about onequarter (24.6\%) of the population aged 65 and over are living alone (26). Living alone increases after about the age of 50 for women and the age of 70 for men, but more sharply for women (26). Older adults living alone, unable to retrieve their mail from $\mathrm{CMB}$, and without someone to depend on, may face particular challenges that need to be explored. Researchers also need to consider older adults of low socioeconomic status who potentially depend on letter mail due to lack of access to a computer or Internet. These older adults may also have poorer health conditions leading to an increased risk of falling. Further study of the implications of the CMBs conversion on this low-income group is needed. Finally, falls prevention programs for older adults are important to improve education and put in place protective mechanisms, such as physical activity classes, health education programs, environmental improvements, and clear and salted pathways. The World Health Organization Age Friendly Cities (27) initiatives, which include attempts to create safe and accessible environments for all citizens, should be supported as they are instrumental for engaging older adults as advocates for their safety.

\section{Conclusion}

This scoping review of literature revealed that Canada is the first country in the group of G8 countries to eliminate home delivery of mail and convert to the community mailboxes. As a result, little research exists on the potential consequences of the change. Our analysis of peer-reviewed and gray literature concluded that older adults may be at an increased risk of falling in the winter, because they will be required to walk to CMBs and physically retrieve their mail as opposed to getting mail delivered directly to their home. Therefore, research is needed to investigate the implications of this change on the wellbeing of older adults in Canada.

\section{Author Note:}

Since the completion of this literature review, a change in federal government occurred in Canada in October 2015. The Liberal Party of Canada won a majority of seats in The House of Commons and Liberal Party leader Justin Trudeau became the Prime Minister of Canada (28). Days after the election, on October 26, 2015, Canada Post announced it would be temporarily suspending its plan to install CMBs across Canada (29). Representatives from Canada Post stated the crown corporation would be working with the new government to determine the best way to proceed with mail delivery and the challenges facing the Canadian postal system (29).

\section{Acknowledgments}

This literature review was initiated by a group of undergraduate students in a project for Gerontology in Practice, a Community ServiceLearning course in the School of Health Studies, Faculty of Health Sciences, and the Western University in London, Canada. The student authors would like to thank their community partners, Dr. John Trevithick and Geoff Bickerton, for invaluable insights into the facts and opinions surrounding the Canada Post conversion and their support during this project. The student authors also express their deep thanks and gratitude to Dr. Aleksandra Zecevic for her tremendous support throughout 
the course and during the development and creation of this manuscript.

\section{References}

1. Canada Post. Canada Post's five-point action plan. Ready for the future [Internet]. 2013. Available from: https://www.canadapost.ca/cpo/mc/assets/pdf/aboutus/5_en.pdf

2. Canada Post. The future of Canada Post. Our consultation with Canadians. [Internet]. Canada Post; 2013. Available from: https://www.canadapost.ca/cpo/mc/assets/pdf/aboutus/c_en.pdf

3. House of Commons. Hansard 36. House of Commons; 2014.

4. United Way. Seniors vulnerability report. [Internet]. United Way; 2011. Available from: http://www.theprovince.com/pdf/uw_2011_seniors_vulnerability_report_low-rez_final.pdf

5. Public Health Agency of Canada. Seniors' falls in Canada [Internet]. Ottawa: Public Health Agency of Canada; 2014. Available from: http://www.phac-aspc.gc.ca/seniorsaines/publications/public/injuryblessure/seniors_falls-chutes_aines/assets/pdf/seniors_falls-chutes_aineseng.pdf

6. Conference Board of Canada. The future of Postal Service in Canada [Internet]. Conference Board of Canada; 2013. Available from: http://www.conferenceboard.ca/elibrary/abstract.aspx?did $=5$

7. McKenna B. Canada Post CEO defends delivery cuts, says seniors will get more exercise. The Globe and Mail [Internet]. 2013 [cited May 2015];. Available from: http://www.theglobeandmail.com/news/politics/canada-postceo-to-be-questioned-by-mps-in-emergency-session/article16024432/
8. Ontario Society (Coalition) of Senior Citizens' Organizations. Pre-Budget Consultation Submission to Alice Wong, Minister of State (Seniors). [Internet]. 2014. Available from: http://www.ocsco.ca/uploads/Image/Federal_preBudget_Submission_Jan_2014rev_4.pdf

9. Federation of Canadian Municipalities. Community mailboxes- FCM's principles for community consultation on the fivepoint action plan [Internet]. 2014. Available from: http://www.fcm.ca/home/issues/more-issues/community-mailboxes.htm

10. City of Burnaby. Community impacts of the proposal to eliminate home mail delivery service by the Canada Post Corporation. [Internet]. 2014. Available from: http://www.newwestcity.ca/council_minutes/0317_14_CW/19d.\%20Corresp\%20- \%20City\%20of\%20Burnaby\%20re\%20impacts\%20of\%20elimination\%20of\%20door\%2 0to\%20door\%20mail\%20delivery.pdf

11. CBC News. Canada Post court challenge launched to save home mail delivery. CBC News [Internet]. 2014 [cited 16 October 2014]; . Available from:

http://www.cbc.ca/news/politics/canadapost-court-challenge-launched-to-savehome- mail-delivery-1.2800697

12. Feith J. Montreal calls for moratorium on Canada Post's community mailboxes. The Montreal Gazette [Internet]. 2015 [cited 3 March 2015];. Available from: http://montrealgazette.com/news/local-news/montreal-calls-for-moratorium-on-canadaposts-community-mailboxes

13. Dehaas J. Phasing out door-to-door mail delivery isn't practical: Mayor Tory. CTV Toronto [Internet]. 2014 [cited 5 June 2015];. Available from: http://toronto.ctvnews.ca/phasing- out-door-todoor-mail-delivery-isn-t-practical-mayortory-1.2154978 
14. CTV Atlantic. Halifax MP urges Canada Post to rethink cancellation of door-todoor delivery. [Internet]. 2015 [cited 5 June 2015]; . Available from: http://atlantic.ctvnews.ca/halifax-mp-urges-canadapost-to-rethink-cancellation-of-door- todoor-delivery-1.2192066

15. Branswell $\mathrm{H}$. As fall heads towards winter it's time to think about how not to fall. The Vancouver Sun [Internet]. 2014 [cited 14 November 2014];. Available from: http://www.vancouversun.com/mobile/life/top-stories/fall+heads+towards+winter+time+think+about+fall/10371302/story .html

16. Björnstig U, Björnstig J, Dahlgren A. Slipping on ice and snow-elderly women and young men are typical victims. Accident Analysis \& Prevention. 1997;29(2):211215.

17. Ralis Z, Barker E, Leslie I, Morgan W, Ross A, White S. SNOW-AND-ICE FRACTURE IN THE UK, A PREVENTABLE EPIDEMIC. The Lancet. 1988;331(8585):589-590.

18. Billesbolle P, Dahl-Knudsen J, Schor J, Mathiesen B. Injury patterns on the first icy day of winter- a survey in Copenhagen County. Ugeskr Laeger. 1989;(151):18051807.

19. Bentley T, Haslam R. Identification of risk factors and countermeasures for slip, trip and fall accidents during the delivery of mail. Applied Ergonomics. 2001;32(2):127134.

20. Bickerton G. 2011CrossTab urban2011_CUPW.PDF: Injury info. 2014.

21. Hill S. Windsor man gets eight stiches with his mail, blames Canada Post for not removing snow. The Windsor Star [Internet]. 2015 [cited 17 May 2015];. Available from: http://blogs.windsorstar.com/news/windsor-senior-gets-eight-stitches-with-hismail- blames-canada-post-for-not-removing-snow
22. McKay J. Senior falls getting mail, worries others may as well. Kingston Whig-Standard [Internet]. 2014 [cited 13 May 2015];. Available from: http://www.thewhig.com/2014/02/09/senior-falls-gettingmail-worries-others-may-as- well

23. Beynon C, Wyke S, Jarman I, Robinson M, Mason J, Murphy K et al. The cost of emergency hospital admissions for falls on snow and ice in England during winter 2009/10: a cross sectional analysis. Environ Health. 2011;10(1):60

24. Public Health Agency of Canada. The facts: seniors and injury in Canada. [Internet]. Ottawa: Public Health Agency of Canada; 2011. Available from: http://www.phacaspc.gc.ca/seniors-aines/publications/public/injury-blessure/safelive-securite/chap2- eng.php

25. Zecevic A, Chesworth B, Zaric G, Huang Q, Salmon A, McAuslan D et al. Estimating the Cost of Serious Injurious Falls in a $\mathrm{Ca}$ nadian Acute Care Hospital. Can J Aging. 2012;31(02):139-147.

26. Statistics Canada. Living arrangements of seniors [Internet]. Ottawa: Statistics Canada; 2011. Available from:

http://www12.statcan.gc.ca/census-recensement/2011/as-sa/98-312-x/98- 312x2011003_4-eng.pdf

27. World Health Organization. Global Agefriendly Cities: A guide. [Internet]. World Health Organization; 2007. Available from: http://www.who.int/ageing/publications/Global_age_friendly_cities_Guide_English.pdf

28. Blackwell, T. Canadian election 2015 hands Justin Trudeau and the Liberals a majority government. National Post [Internet]. 2015 [Cited 9 February 2016];. Available from: http://news.nationalpost.com/news/canada/canadian-politics/canadian-election2015-liberals-jump-to-early-lead-as-pollsclose-in-newfoundland-and-labrador 


\section{Research article}

29. Tait, C., \& Perreaux, L. Canada Post suspends plan to install community mail-

boxes. The Globe and Mail [Internet]. 2015

[Cited 9 February 2016]; . Available from:

http://www.theglobe-

andmail.com/news/politics/canada-post-

erecting-community-mailboxes-despite-

liberal-delivery-pledge/article26981780/ 